\title{
Particulate Mercury in the Atmosphere: Its Significance, Transport, Transformation and Sources
}

\author{
G. KEELER, G. GLINSORN and N. PIRRONE \\ The University of Michigan Air Quality Laboratory, Ann Arbor, MI 48109-2029
}

\begin{abstract}
The importance of particulate mercury $(\mathrm{Hg}(\mathrm{p}))$ in the transport, chemistry and deposition of this toxic metal has long been underestimated and largely ignored. While it was once believed to constitute a small percentage of total atmospheric mercury, $\mathrm{Hg}(p)$ may contribute a significant portion of the deposition of this metal to adjacent natural waters. Recent measurements of $\mathrm{Hg}(\mathrm{p})$ in several urban/industrial areas have documented that $\mathrm{Hg}$ can be associated with large particles $(>2.5 \mu \mathrm{m})$ and in concentrations similar to those of the vapor phase $\mathrm{Hg}\left(\mathrm{ng} / \mathrm{m}^{3}\right)$. As part of ongoing effort to diagnose the sources, transport and deposition of $\mathrm{Hg}$ to the Great Lakes and other Great Waters, the University of Michigan Air Quality Laboratory (UMAQL) has investigated the physical and chemical properties of particulate-phase $\mathrm{Hg}$ in both urban and rural locations. It appears that particulate $\mathrm{Hg}$ may be the one of the most difficult of the $\mathrm{Hg}$ measurements to perform, and perhaps the one of the most important for deposition and source apportionment studies. Particulate $\mathrm{Hg}$ concentrations measured in rural areas of the Great Lakes Region and Vermont ranged from 1 to $86 \mathrm{pg} / \mathrm{m}^{3}$ whereas $\mathrm{Hg}(\mathrm{p})$ levels in urban/industrialized areas were in the range $15 \mathrm{pg} / \mathrm{m}^{3}$ to $1.2 \mathrm{ng} / \mathrm{m}^{3}$.
\end{abstract}

Keywords: Mercury, dry deposition, particle phase mercury, size distribution, Great Lakes, Lake Champlain

\section{Introduction}

In recent years, the behavior of hazardous air pollutants (HAPs) has been receiving a great deal of attention from the scientific community. This is largely the result of recent changes in regulations including the Clean Air Act Amendments of 1990 and due to the scientific interest associated with compounds with inherent chemical and physical complexities. Mercury ( $\mathrm{Hg}$ ) continues to be of special concern because of its multitude of controllable sources, its volatility, mobility and strong tendency to bioaccumulate. In the Great Lakes Region, research on the sources, transport and deposition of atmospheric mercury has gained increasing attention as it is now believed by many to be the most important pathway for inputs to the natural waters.

The processes and deposition rates by which mercury enters the water column are still not adequately understood. In particular, the role of the various physical/chemical forms of mercury deposited from the atmosphere has yet to be determined. While vapor phase mercury is thought to constitute the vast majority of the atmospheric mercury burden, particle-phase mercury may actually play a disproportionately large role in the amount of $\mathrm{Hg}$ in the various environmental compartments. While the relative importance of wet deposition versus dry deposition in delivering $\mathrm{Hg}$ to the earth's surface is largely unknown, and location specific, most researchers agree that the particulate form of $\mathrm{Hg}$ is critical in understanding the cycling of this metal in the environment. 
An important aspect of this research was the ability to accurately collect and effectively analyze $\mathrm{Hg}(\mathrm{p})$ without artifacts. Measurements of $\mathrm{Hg}(\mathrm{p})$ has been limited over the past two decades but with recent advances in instrumental sensitivity and the application of clean techniques our knowledge of $\mathrm{Hg}(\mathrm{p})$ concentrations and behavior has improved. The precise determination of ultra-trace environmental concentrations $\left(\mathrm{pg} / \mathrm{m}^{3}\right)$ of $\mathrm{Hg}(\mathrm{p})$ are now feasible. Until now, the number of studies with high quality $\mathrm{Hg}(\mathrm{p})$ data has been limited to a few intensive efforts.

The Air Quality Laboratory at the University of Michigan (UMAQL) has developed (Keeler, 1994; Lamborg et al., 1994) and continues to improve the methods to reliably collect and analyze size fractionated $\mathrm{Hg}(\mathrm{p})$. These techniques are presently being utilized to gain a wider understanding of the atmospheric mercury cycle. Various analytical techniques have been utilized including dual-amalgamation preconcentration and cold vapor atomic fluorescence spectrometric (CVAFS) detection performed on $\mathrm{Hg}(\mathrm{p})$ extracted from glass fiber and other types of filters, and instrumental neutron activation analysis (INAA) performed on Teflon filters. The different techniques have distinct advantages and have been used to quantify $\mathrm{Hg}(\mathrm{p})$ in recent studies (Keeler et al., 1994; Lamborg et al., 1994; Olmez et al., 1994).

Atmospheric $\mathrm{Hg}$ measurements reported here were performed as part of several UMAQL studies including: 1) ongoing urban atmospheric chemistry and deposition studies in Detroit, MI (Keeler et al., 1994); 2) a two-year multi-site atmospheric $\mathrm{Hg}$ transport and deposition study in the State of Michigan (Hoyer et al., this volume); 3) a long-term $\mathrm{Hg}$ and pollutant cycling study in the Lake Champlain Basin of Vermont (Burke et al., this volume); and 4) a study of the atmospheric $\mathrm{Hg}$ levels in Broward County, Florida (Dvonch et al., this volume). These investigations have provided an indepth look at the relationship between particulate mercury and other aerosol constituents. In addition, mercury bound to particulate matter in precipitation is currently under investigation in event precipitation samples collected at the rural locations in Michigan and in the Lake Champlain Basin. This paper aims to evaluate the $\mathrm{Hg}(\mathrm{p})$ data collected by the UMAQL to date and to provide evidence of it's importance in the cycling of this critical pollutant.

\section{Sampling and Analysis}

Ultra-clean sampling and analysis techniques were required to obtain reliable $\mathrm{Hg}(\mathrm{p})$ data. Sampling equipment including filter packs, forceps, vials, petri dishes as well as other field sampling equipment were rigorously acid-cleaned in a 5-step, 11-day process. All sampling equipment, including filter packs and cyclones, were constructed of Teflon or were Teflon coated. Glass-fiber filters were pre-fired at $500^{\circ} \mathrm{C}$ for $>1$-hour prior to use in sampling. During sample collection, particle-free gloves were worn when field equipment was handled. Since outdoor concentrations of $\mathrm{Hg}$ in all forms are typically lower than indoor concentrations, most of the handling of filters and filter packs was done outdoors.

Total particulate mercury $(\mathrm{Hg}(\mathbf{p}))$ was collected using an open-faced Teflon filter pack onto $47 \mathrm{~mm}$ glass fiber filters (Gelman Type A/E) for 24 hours at a nominal flow rate of $30 \mathrm{~L} \mathrm{~min}^{-1}$. Mercury in the fine particle size range $(<2.5 \mu \mathrm{m})$ was collected onto $47 \mathrm{~mm}$ diameter glass-fiber filters using Teflon coated aluminum cyclones (URG, Carboro NC) 
to remove larger particles upstream of the filter. Filters were placed into acid-cleaned petri dishes immediately after sampling, Teflon-taped and then stored at $-40^{\circ} \mathrm{C}$ until analysis.

In addition, a microorifice cascade impactor (MOI) was used to collect sizefractionated aerosols (Marple and Rubow, 1984). This impactor was chosen because of its moderately high flow rate, $30 \mathrm{~L} \mathrm{~min}^{-1}$, and relatively low pressure drop. With an ambient pressure of $0.973 \mathrm{~atm}$ the measured pressures at the nozzle exit of the five stages are $0.973,0.971,0.942,0.929$, and $0.893 \mathrm{~atm}$, respectively. Regulation of the pressure drop is important as vaporization of particle associated water inside the impactor can result in a distortion of the size distribution (Biswas et. al., 1987). This water loss could cause the particles to become smaller, resulting in an underestimate of the particles aerodynamic size. Experiments carried out with sulfuric acid droplets showed maximum changes in particle size of $3 \%$. Since it is unclear whether the particulate $\mathrm{Hg}$ is associated with the sulfur containing particles in the atmosphere the actual size distortion of the $\mathrm{Hg}$ laden particles may be different but should not exceed that of highly hygroscopic sulfate. Teflon membrane filters $(2 \mu \mathrm{m}$ pore size) and glass-fiber filters were both utilized as impaction surfaces as they have low blanks for $\mathrm{Hg}$. The particle cut-off diameters for the first 5 impactor stages are 5.0, 2.5, 1.0, 0.6, and $0.18 \mu \mathrm{m}$, respectively. The last stage collects all particles below $0.18 \mu \mathrm{m}$ is aerodynamic size.

The filter extraction and analysis was performed in a Class 100 cleanroom using reagents that required further purification to maintain the consistently low blank values and detection limits. The present UMAQL protocol, utilized in the analysis of the MOI and Detroit filters, involved the extraction of each glass fiber filter in $30 \mathrm{~mL}$ of $10 \%$ $\mathrm{HNO}_{3}$ followed by a digestion of the filter for 20 minutes at $160^{\circ} \mathrm{C}$ using a CEM MDS2000 computer controlled microwave unit. The samples were then allowed to react for 12-hours at room temperature. After digestion, $10 \mathrm{~mL}$ of extract were removed with a pipet and placed into $30 \mathrm{~mL}$ acid cleaned polyethylene bottle for trace metals analysis using a Perkin Elmer ELAN 5000 ICP-MS. The remaining extract was utilized for $\mathrm{Hg}$ analysis by prior addition of $0.25 \mathrm{~mL}$ of $\mathrm{BrCl}$ to oxidize all the $\mathrm{Hg}$ to $\mathrm{Hg}^{2+}$. The glass fiber filters used in the MOI were extracted with only $10 \mathrm{~mL}$ of $10 \% \mathrm{HNO}_{3}$ and were then treated as described above.

The UMAQL standard particulate protocol, applied to all filters collected in the Michigan Network, Vermont Studies, and Florida Study utilized acid digestion/CVAFS analysis of the samples extracted in a $10 \%$ solution of a $70 \%$ nitric acid $/ 30 \%$ sulfuric acid mixture (approximately $2 \mathrm{~N}$ ) in Teflon vials. Extraction was performed by placing the vials in a sonic bath for 30 minutes. After extraction, the solution was oxidized with $\mathrm{BrCl}$ for one hour, converting all forms of $\mathrm{Hg}$ present into the inorganic, +2 oxidation state. The sample was reduced with $\mathrm{NH}_{2} \mathrm{OH}$ and $\mathrm{SnCl}_{2}$ was added to convert the $\mathrm{Hg}^{2+}$ to $\mathrm{Hg}^{\circ}$ which is volatile and liberated from solution by bubbling with $\mathrm{Hg}$-free $\mathrm{N}_{2}$. The $\mathrm{Hg}$ released in this way was collected on Au-coated sand traps. The $\mathrm{Hg}$ was subsequently analyzed using the dual-amalgamation CVAFS method described by Fitzgerald $e t$ al. (1979). A calibration curve was generated by spiking vials containing blank filters with varying amounts of a $2 \mathrm{ng} / \mathrm{mL}$ standard (in $1 \% \mathrm{BrCl}$ ).

Flow rates through the sampling systems were measured using both calibrated rotameters with filter packs used only for flow-tests to prevent contamination, and 
frequently calibrated dry test meters. Sampling pumps with mass flow-controllers were typically used to pull ambient air through the sampling equipment. All flow checking devices are calibrated before and after all intensive field projects with primary flow calibration equipment (e.g. spirometer).

\subsection{QUALITY CONTROL AND QUALITY ASSURANCE}

The UMAQL utilizes ultra-clean technique in all facets of the collection and analysis of our environmental samples (Keeler et al., 1994). All equipment and supplies used in sampling are rigorously acid-cleaned in a 5-step, 11-day procedure (Rossman and Barres, 1991). Sample bottles, Au-sand traps and glass-fiber filter containers are Teflon-taped and triple-bagged before and after each use in the field. Particle-free gloves are always worn when handling the samples in the field as well as in the Class 100 clean laboratory at the University of Michigan.

Field and storage blanks were collected regularly with the particulate $\mathrm{Hg}$ samples. The field blanks were collected by loading the acid-cleaned filter packs and assemblies, connecting the sampling equipment, and then placing the filter pack assemblies or impactors in the sampling box for two minutes without drawing air through the system. Field and storage blanks for particulate $\mathrm{Hg}$ averaged $<7 \mathrm{pg} \mathrm{Hg}$ per filter (equivalent of $<0.17 \mathrm{pg} / \mathrm{m}^{3}$ for a $24-$ hour sample). Storage blanks for particulate mercury were obtained by placing an unused pre-fired glass fiber filter in a petri dish and shipping it to UMAQL for analysis.

A reagent blank was analyzed on each day of particulate $\mathrm{Hg}$ analysis. The appropriate amounts of reagents were analyzed to determine the contribution of the reagents to the concentration of $\mathrm{Hg}$ obtained for the sample. All samples were blank corrected using the corresponding reagent blank analyzed that day. The detection limit calculated as three times the standard deviation of reagent blanks, was less than $1 \mathrm{pg} / \mathrm{m}^{3}$ for total particulate $\mathrm{Hg}$. Initially, all particulate $\mathrm{Hg}$ samples were routinely analyzed in duplicate, and more recently, $50 \%$ of all samples were analyzed in duplicate. The analytical precision calculated from these replicate analyses was better than $10 \%$ for the routine analysis of $\mathrm{Hg}(\mathrm{p})$ in all of the studies. An initial analytical comparison was performed to compare the UMAQL extraction techniques to INAA performed on a "whole" undigested sample. Standard Reference Material No. 1648 from the National Institute of Standards and Technology (NIST) was obtained for this purpose. Urban Particulate Material (UPM) was extracted using the routine protocol as well as by INAA at the MIT Nuclear Reactor Laboratory. The two techniques gave equivalent results $(1.02 \pm .05$ vs. $1.07 \pm .1)$ for the UPM (Olmez, personal communication). However, this does not guarantee that atmospheric aerosol samples would behave identically, therefore, additional experiments with collocated ambient filter samples are being completed to investigate this question.

\section{Results and Discussion}

\subsection{MERCURY SIZE DISTRIBUTION IN URBAN DETROIT}

The levels of vapor and particulate $\mathrm{Hg}$ have been previously measured in the City of Detroit during a short duration study in 1992 (Keeler et al., 1994). Levels of particulate 
$\mathrm{Hg}$ varied greatly from one site to the other with maximum concentrations at both sites of greater than $1 \mathrm{ng} / \mathrm{m}^{3}$. In the present study the atmospheric $\mathrm{Hg}$ levels were measured at only one site during the spring of 1994. The fine and total $\mathrm{Hg}(\mathrm{p})$ concentrations measured in Detroit for 18 consecutive days during March of 1994 are displayed in Figure 1.

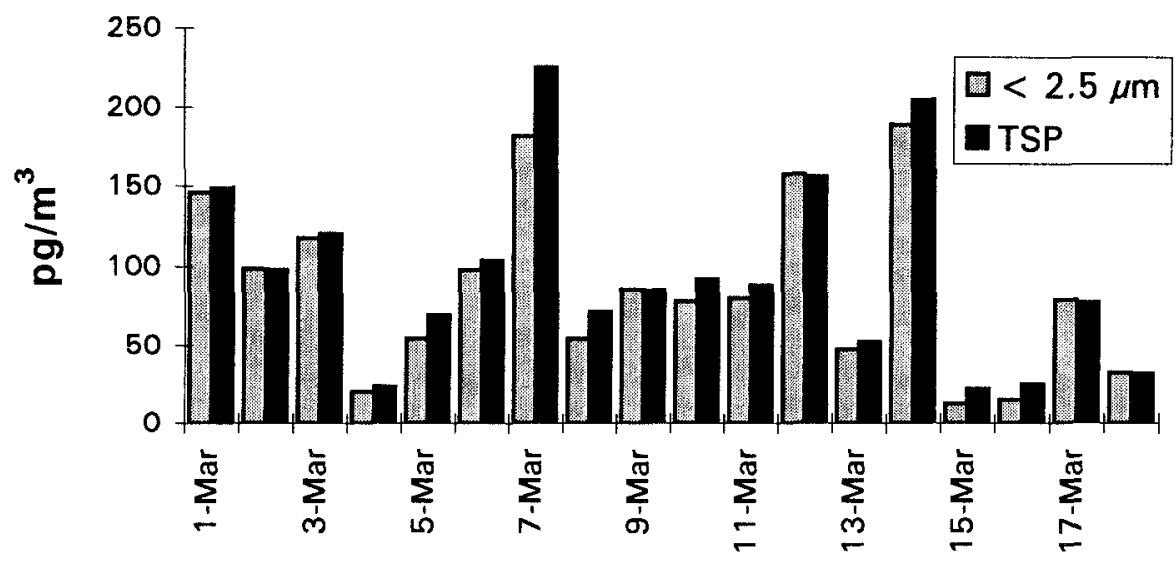

Figure 1. Fine and coarse particulate Hg concentrations measured in Detroit in March, 1994.

Ambient samples were collected every day during the study period for both fine particles $(<2.5 \mu \mathrm{m})$ and for total suspended particulates (TSP). The average total particulate $\mathrm{Hg}$ concentration during the study period was $94 \mathrm{pg} / \mathrm{m}^{3}$ with a range of 22 to $225 \mathrm{pg} / \mathrm{m}^{3}$. The percent of particulate $\mathrm{Hg}$ found in the fine size range $(<2.5 \mu \mathrm{m})$ varied from about $60 \%$ to $100 \%$ during the 18 days of sampling. The mean \%fine for the period was $\mathbf{8 8 \%}$ as compared to $\mathrm{Cd}$, another anthropogenically derived element which was measured concurrently, had an average of only $72 \%$ of its mass in the fine fraction.

The complete size distribution of the particulate $\mathrm{Hg}$ was measured with the $\mathrm{MOI}$ for each of the 18 days of sampling in downtown Detroit. The results indicate that particulate $\mathrm{Hg}$ was mostly collected on the fourth and fifth impactor stages. The mass median diameters (MMD) for these stages are 0.60 and $0.18 \mu \mathrm{m}$, respectively. Particles less than $0.18 \mu \mathrm{m}$ were collected on the back-up filter. The results from the measurements in Detroit were compared to those compiled by Milford and Davidson (1985) from three references to particulate $\mathrm{Hg}$ measurements made in the late 1970 s and early ' $80 \mathrm{~s}$. A total of five measurements in the three studies were utilized to calculate a MMD of $0.61 \mu \mathrm{m}$. The range in the five concentrations measured was $0.08-81 \mathrm{ng} / \mathrm{m}^{3}$ with a geometric mean concentration of $1.9 \mathrm{ng} / \mathrm{m}^{3}$. The MMD calculated from the 18 days of measurements in Detroit was $0.80 \mu \mathrm{m}$. The larger MMD observed in Detroit was associated with a much lower mean concentration than the older studies reported in the review paper by Milford and Davidson (1985).

The distribution of particulate $\mathrm{Hg}$ in Detroit was bimodal with an obvious fine and coarse mode. The average particle size for $\mathrm{Hg}(\mathrm{p})$ in the fine and coarse fractions was 
determined using stages one and two of the MOI to calculate the average particle size of coarse fraction $(>2.5 \mu \mathrm{m})$, and stages three through six to calculate the particle size of fine fraction $(<2.5 \mu \mathrm{m})$. The average particle size of the $\mathrm{Hg}(\mathrm{p})$ in each mode was 0.68 $\mu \mathrm{m}$ and $3.78 \mu \mathrm{m}$ for fine and coarse particles, respectively. The observation of the coarse particle mode was somewhat unexpected as previous studies have suggested that $\mathrm{Hg}(\mathrm{p})$, being primarily a combustion aerosol, should be submicron in size. In Detroit adsorption of vapor phase $\mathrm{Hg}$ onto existing aerosols was apparent with a positive relationship between $\mathrm{Hg}(\mathrm{p})$ and the total particulate mass in the atmosphere. The importance of the coarse particle $\mathrm{Hg}$ can be seen in the relative contribution of these large particles to the dry deposition flux. Modeling the dry deposition flux using the size distributions from this study demonstrated that the flux of coarse particle $\mathrm{Hg}$ was 4-5 times greater than the fine particle flux (Pirrone $e t$ al., this volume).

An analysis of $\mathrm{Hg}(\mathrm{p})$ concentrations observed in Wayne County, MI at nine sites revealed that $\mathrm{Hg}$ levels increased by $11 \%$ annually over the period from 1986-1992 (Pirrone et al., 1994). The significant increase in the annual particulate $\mathrm{Hg}$ levels was directly related to a $3 \%$ annual increase in coal consumption in Michigan together with an increase of $13 \%$ in the quantity of wastes being incinerated in the City of Detroit.

The concentrations observed in Detroit are similar to those recently reported for a long-term study of atmospheric particles in urban areas of the United Kingdom (Lee et al., 1994). Quarterly average $\mathrm{Hg}(\mathrm{p})$ concentrations were in the range of 90 to $540 \mathrm{pg} / \mathrm{m}^{3}$ for the ten UK sites discussed. The highest $\mathrm{Hg}(\mathrm{p})$ concentrations were observed at a site located near a smelter which also resulted in the highest concentrations observed for a variety of other heavy metals. The levels of particulate $\mathrm{Hg}$ in the $\mathrm{UK}$ study as well as those reported here are at the lower end of those reported for urban locations by Schroeder et al. (1987). The elevated concentrations of particulate $\mathrm{Hg}$ in urban areas suggests that more attention should be given to both nonferrous metal smelters and incinerators as sources of $\mathrm{Hg}(\mathrm{p})$ to the atmosphere.

\subsection{PARTICULATE MERCURY IN RURAL MICHIGAN}

In the previous section the levels of $\mathrm{Hg}(\mathrm{p})$ measured in the urban/industrial area of Detroit, MI were discussed. The typical levels in the urban/industrial areas and the variability of these levels was much greater than those typically observed at the more rural sites in Michigan, Pellston (PEL), South Haven (SHA), and Ann Arbor (ANN). Ambient measurements were performed every sixth-day for one-year at three rural sites in Michigan (Hoyer et al., this volume). Particulate mercury levels averaged $10.5 \mathrm{pg} / \mathrm{m}^{3}$ at PEL $(\mathrm{n}=47), 22.4 \mathrm{pg} / \mathrm{m}^{3}$ at SHA $(\mathrm{n}=52)$ and $21.9 \mathrm{pg} / \mathrm{m}^{3}$ at ANN $(\mathrm{n}=54)$. The range in particulate mercury concentrations observed at the South Haven and Ann Arbor sites was much greater than that recorded at Pellston (Figure 2).

Particulate $\mathrm{Hg}$ displayed a seasonal behavior at the rural Michigan sites. The maximum particulate mercury concentrations were recorded during the winter and early spring with a maximum 24-hour concentration of $32.2 \mathrm{pg} / \mathrm{m}^{3}$ observed at Pellston (8 Apr. 94), $85.7 \mathrm{pg} / \mathrm{m}^{3}$ at South Haven (20 Jan 94) and $76.9 \mathrm{pg} / \mathrm{m}^{3}$ at Ann Arbor (8 Jan 94). 
The range in the $\mathrm{Hg}(\mathrm{p})$ was also not as dynamic at the site in the northern-most part of the lower peninsula of Michigan. The maximum concentrations of $\mathrm{Hg}(\mathrm{p})$ at Pellston in northern Michigan were less than $50 \%$ of those observed at the two southern Michigan sites. Particulate $\mathrm{Hg}$ concentrations exceeded $30 \mathrm{pg} / \mathrm{m}^{3}$ only 2 times during the year of measurement at Pellston. Air mass trajectories calculated for these days revealed that elevated concentrations were associated with transport was from the urban areas to the southwest and southeast to the site. Elevated $\mathrm{Hg}(\mathrm{p})$ measured at South Haven and Ann Arbor were typically associated with transport from the east and the southwest.

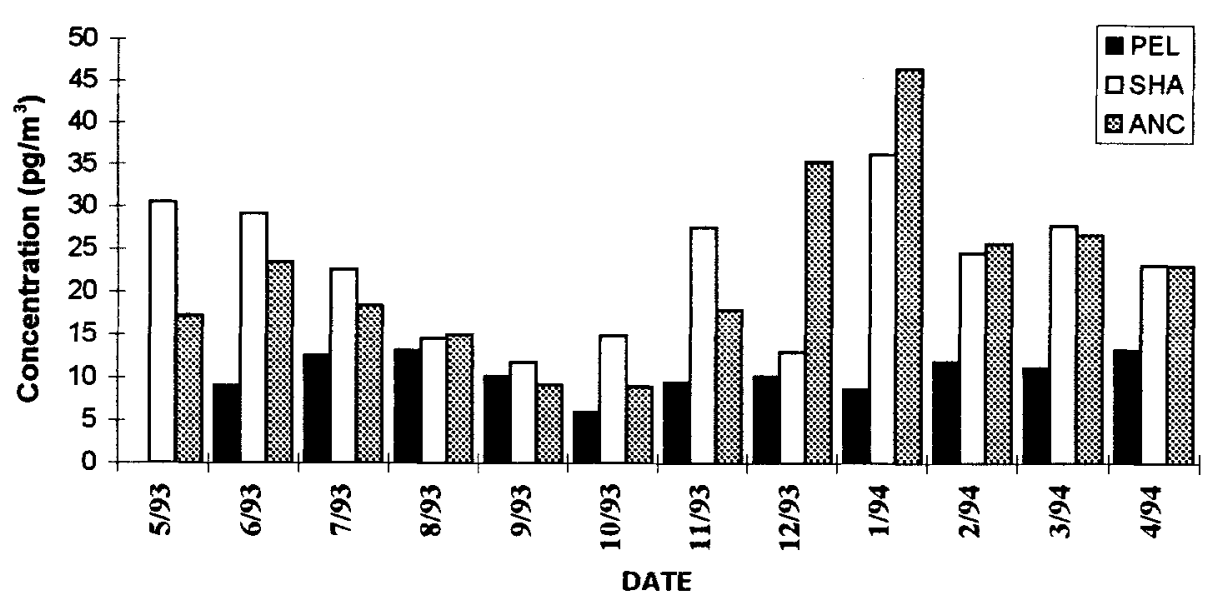

Figure 2. Monthly averaged particulate $\mathrm{Hg}$ concentrations at three Michigan sites.

\subsection{PARTICULATE MERCURY IN RURAL VERMONT}

Atmospheric $\mathrm{Hg}$ samples were collected twice per week with a total of 103 particulate phase $\mathrm{Hg}$ samples collected during 1993. The annual arithmetic average $\mathrm{Hg}(\mathrm{p})$ and vapor phase $\mathrm{Hg}$ concentration was $11.2 \mathrm{pg} / \mathrm{m}^{3}$ and $2.0 \mathrm{ng} / \mathrm{m}^{3}$, respectively. While the vapor phase concentrations at Underhill displayed no strong seasonal behavior a seasonal trend was observed in the $\mathrm{Hg}(\mathrm{p})$ with elevated concentrations during the winter months. This was especially evident in February where all samples were above the annual average. Increasing concentrations in November and December of 1993 provide further support for a seasonal influence on particulate $\mathrm{Hg}$ concentrations at this site. A similar increase in the concentration of other metals such as As and Se measured at Underhill (NESCAUM data) during the winter months was also observed. A similar increase in particulate $\mathrm{Hg}$ concentration during the winter months was observed at the rural sites in Michigan, as discussed in the previous section.

The seasonally averaged particulate $\mathrm{Hg}$ concentrations further illustrate this trend (Table I). The average for the winter months is significantly greater than the annual 
mean, and the spring and autumn averages are somewhat higher than the average for summer.

Concurrent measurements of $\mathrm{Hg}$ in precipitation and ambient air (daily vapor and particulate) were obtained at the Underhill site (Burke et al., this volume). Simple correlations were calculated between ambient and precipitation concentrations for the sampling days when precipitation occurred during ambient measurements. Ambient particulate $\mathrm{Hg}$ was correlated with reactive $\mathrm{Hg}$ in precipitation $(\mathrm{r}=0.654, \mathrm{p}<0.02, \mathrm{n}=13)$.

TABLE I

Seasonal averages for particulate $\mathrm{Hg}$ at Underhill, VT during 1993

\begin{tabular}{ccc}
\hline Season & $\mathbf{N}$ & $\begin{array}{c}\mathbf{H g}(\mathbf{p}) \\
\left(\mathbf{p g} / \mathbf{m}^{3}\right)\end{array}$ \\
\hline Winter & 24 & 15.8 \\
Spring & 26 & 9.7 \\
Summer & 26 & 9.4 \\
Autumn & 25 & 10.0 \\
\hline
\end{tabular}

\subsection{PARTICULATE MERCURY IN BROWARD COUNTY SOUTH FLORIDA}

Particulate $\mathrm{Hg}$ samples were taken concurrently at three sites during the period 25 August to 7 September (Dvonche et al., this volume). The average concentrations at the inland locations, sites 2 and 3 , were $51 \mathrm{pg} / \mathrm{m}^{3}$ and $49 \mathrm{pg} / \mathrm{m}^{3}$, respectively. The average $\mathrm{Hg}(\mathrm{p})$ measured at site 1 near the beach, located about $9 \mathrm{~km}$ east of sites 2 and 3, was 34 $\mathrm{pg} / \mathrm{m}^{3}$. Particulate phase $\mathrm{Hg}$ comprised less than $5 \%$ of the total atmospheric $\mathrm{Hg}$ (vapor and particulate) which was consistent with values reported in northern locations (Burke et al., this volume). The levels of $\mathrm{Hg}(\mathrm{p})$ in Broward County were generally higher than those typically measured (about $10-30 \mathrm{pg} / \mathrm{m}^{3}$ ) at the rural sites in the Great Lakes Basin, discussed earlier. The levels measured in Broward County were not as high as other measurements made in large urban/industrial source areas such as Detroit, where shortterm average particulate $\mathrm{Hg}$ concentrations were found to be near $100 \mathrm{pg} / \mathrm{m}^{3}$. However, the elevated levels of particulate $\mathrm{Hg}$ observed in Broward County during were higher than those measured at rural sites with concentrations never exceeding $100 \mathrm{pg} / \mathrm{m}^{3}$. The elevated levels in Broward county are suggestive of a local source influence. The elevated levels of $\mathrm{Hg}(\mathrm{p})$ in South Florida were somewhat surprising. While the average vapor phase $\mathrm{Hg}$ levels were 2-3 times higher in Broward County than those measured elsewhere, the PM10 and TSP levels were not significantly elevated with typical concentrations of PM10 in the range $15-20 \mu \mathrm{g} / \mathrm{m}^{3}$. 


\section{Conclusions}

Measurements of $\mathrm{Hg}(\mathrm{p})$ documented the importance of this form of the compound in the atmosphere. The levels and behavior of $\mathrm{Hg}(\mathrm{p})$ was investigated at several locations in the Great Lakes, Lake Champlain basin, and in South Florida. The magnitude and particle size of the observed $\mathrm{Hg}(\mathrm{p})$ varied dramatically from site-to-site as well as from day-to-day. Seasonal variability was observed in the levels of $\mathrm{Hg}(\mathbf{p})$ with higher concentrations typically found in the winter months than those measured in the summer. The observed correlation between the operationally-defined reactive $\mathrm{Hg}$ species and $\mathrm{Cl}^{-}$ in precipitation provides support for the speculation that this species may be $\mathrm{HgCl}_{2}$. Also, the correlation observed between ambient particulate $\mathrm{Hg}$ and reactive $\mathrm{Hg}$ species in precipitation on days when ambient measurements were conducted and precipitation occurred, implies that this species may be associated with particles.

The average particle size of the $\mathrm{Hg}(\mathrm{p})$ measured in each mode was $0.68 \mu \mathrm{m}$ and 3.78 $\mu \mathrm{m}$ for fine and coarse particles, respectively. The observation of the coarse particle mode was somewhat unexpected as previous studies have suggested that $\mathrm{Hg}(\mathrm{p})$ should be submicron in size. Near source adsorption of vapor phase $\mathrm{Hg}$ onto existing aerosols was apparent in Detroit with a positive relationship between $\mathrm{Hg}(\mathrm{p})$ and total particulate mass in the atmosphere. The importance of large particle $\mathrm{Hg}(\mathrm{p})$ should not be underestimated in determining the dry deposition flux. Modeling the dry deposition demonstrated that the flux of coarse particle $\mathrm{Hg}$ was 4-5 times greater than the fine particle flux in this study. The relative importance of $\mathrm{Hg}(\mathrm{p})$ in the fine and coarse fractions to the total dry deposition flux was site specific and varied with time and meteorological conditions.

\section{Acknowledgments}

This work was supported by the Michigan Great Lakes Protection Fund, the University of Michigan, Cooperative Institute of Liminology and Ecosystems Research (CILER) under cooperative agreement from the Environmental Research Laboratory (ERL), National Oceanographic and Atmospheric Administration (NOAA)., US Department of Commerce under Cooperative Agreement No. NA90RAH00079, the State Of Florida Department of Environmental Protection, and cooperative research agreements with the US EPA -Atmospheric Research and Exposure Assessment Laboratory (AREAL). The success of these projects was the result of the hard work of our dedicated site operators: Robert Vande Kopple (Pellston), Mary Barden (South Haven) and Katherine Beverstock (Dexter), Joanne Cummings and Carl Waite (Underhill, VT). We would also like to acknowledge the contribution of several researchers at the University of Michigan Air Quality Laboratory who performed the field sampling and sample analysis including Janet Burke, Tim Dvonch, Marion Hoyer, Anne Rea, and Alan Vette.

\section{References}

Biswas, P., Jones, C.L. and Flagan, R.C.: 1987, J. Aerosol Sci. Technol. 7, 231.

Brosset, C.: 1987, Water, Air and Soil Pollut. 34, 145.

Brosset, C., Andreasson, K. and Ferm, M.: 1975, Atmos. Environ., 7, 631

Burke, J., Hoyer, M., Keeler, G. and Scherbatskoy, T.: Water, Air and Soil Pollut, this volume.

Dvonch, J.T., Vette, A.F., Keeler, G.J., Evans, G. and Stevens, R.: Water, Air and Soil Pollut., this volume.

Iverfeldt, A.: 1991, Water, Air and Soil Pollut. 55, 33.

Iverfeldt, A.: 1991, Water, Air and Soil Pollut. 56, 251. 
Lamborg, C.H., Hoyer, M.E., Keeler, G.J., Olmez, I. and Huang, X.: 1994, In: Mercury as a Global PollutantToward Integration and Synthesis. Watras, C.J. and Huckabee, J. Eds, Lewis Publishers, Boca Raton, Florida.

Lee, D.S., Garland, J.A and Fox, A.A.: 1994, Atmos. Environ. 28, 2691.

Lindberg, S., Turner, R., Meyers, T., Taylor, Jr. G., and Schroeder, W.: 1991, Water, Air and Soil Pollut. 56, 577.

Lindqvist, O.: 1985, Tellus 37B, 136.

Fitzgerald, W.F. and Gill, G.A.: 1979, Anal. Chem. 51, 1714.

Fitzgerald, W., Mason, R. and Vandal, G.: 1991, Water, Air and Soil Pollut. 56, 745.

Hoyer, M., Burke, J., Cleckner, L. Mukherjee, K. and Keeler, G.: 1993, 'Mercury in Precipitation: A Multi-Site Study.' In: Proceedings of the 9th International Conference on Heavy Metals in the Environment. Toronto, Canada.

Keeler, G.J. and Samson, P.J.: 1989, Environ. Sci. Technol., 23, 1358.

Keeler, G.J.: 1994, 'The Lake Michigan Urban Air Toxics Study', Final Report, Atmospheric Research and Exposure Assessment Laboratory, Office of Research and Development, U.S. EPA, Research Triangle Park, N.C.

Keeler, G.J., Hoyer, M.E., and Lamborg, C.: 1994, In: Mercury as a Global Pollutant-Toward Integration and Synthesis. Watras, C.J. and Huckabee, J. Eds, Lewis Publishers, Boca Raton, Florida.

Lamborg, C.H., Hoyer, M.E., Keeler, G.J., Olmez, I. and Huang, X.: 1994, In: Mercury as a Global PollutantToward Integration and Synthesis. Watras, C.J. and Huckabee, J. Eds, Lewis Publishers, Boca Raton, Florida.

Lindberg, S., Turner, R., Meyers, T., Taylor, Jr. G., and Schroeder, W.: 1991, Water, Air and Soil Pollut. 56, 577.

Lindqvist, O.: 1985, Tellus 37B, 136.

Marple, V. and Rubow, K.: 1984, Final Report, Pittsburgh Energy Technol. Center, Pittsburgh, P.A.

Olmez, I., Oakberg, K., Che, J., Coffey, P., Meier, S. and Galvin, P.:1993, In: managing Hazardous Air PollutantsState-of-the-Art. Chow, W. and Chu, P., Eds, Lewis Publishers, Boca Raton, FL.

Pirrone, N., Keeler, G.J. and Warner, P.O.: 1994, Sci. Tot. Environ., In Press.

Pirrone, N., Glinsom, G. and Keeler: Water, Air and Soil Pollut., this volume.

Rossmann, R. and Barres, J.: 1991, J. Great Lakes Res. 14, 188.

Schroeder, W.H., Dobson, M., Kane, D.M and Johnson, N.D. : 1987, JAPCA, 37, 1267. 